\begin{tabular}{|c|c|}
\hline Title & The effects of shrub patch sizes on the colonization of pioneer plants on the volcano Mount Koma, northern Japan \\
\hline Author(s) & Holle, Mukhlish Jamal Musa; Tsuyuzaki, Shiro \\
\hline Citation & $\begin{array}{l}\text { A cta Oecologica: International Journal of Ecology, 93, } 48.55 \\
\text { https://doi.org/10.1016/.actao.2018.10.009 }\end{array}$ \\
\hline Issue Date & 201811 \\
\hline Doc URL & http:/hdl .handle.net/2115/79657 \\
\hline Rights & $\begin{array}{l}\text { @ 2018. This manuscript version is made available under the CC-BY-NC-ND } 4.0 \text { license } \\
\text { http://creativecommons.org/icenses/by-nc-nd/4.0/ }\end{array}$ \\
\hline Rights(URL) & https://creativecommons.org/icenses/by-nc-sa/4.0/ \\
\hline Type & article (author version) \\
\hline File Information & A ctaO eco Mukhlish Jamal Final.pdf \\
\hline
\end{tabular}

Instructions for use 


\title{
The effects of shrub patch sizes on the colonization of pioneer plants on the volcano Mount Koma, northern Japan
}

\author{
Mukhlish Jamal Musa Holle ${ }^{1,2} \&$ Shiro Tsuyuzaki ${ }^{1}$ \\ ${ }^{1}$ Graduate School of Environmental Science, Hokkaido University, Sapporo Japan 060-0810 \\ ${ }^{2}$ Faculty of Biology, Gadjah Mada University, Sleman DI. Yogyakarta Indonesia 55281
}

\begin{abstract}
Vegetation recovery on Mount Koma, Hokkaido, Japan, has been slow after the catastrophic eruption in 1929, due to undeveloped soil and limited plant colonization. Nowadays, the seedling establishment is supported mostly by a nurse plant, Salix reinii forming shrub patches, facilitates the plant colonization. Although the effects of shrub patches should differ with patch sizes, the size effects have not been examined well. To examine the size effects, seed-sowing experiments were conducted on two common pioneer herbaceous species, Miscanthus sinensis and Polygonum sachalinense, in the field. The seed germination and seedling survival were monitored by the seeds sown into $S$. reinii patches $\left(0.97 \mathrm{~m}^{2}\right.$ to $4.12 \mathrm{~m}^{2}$ in area) for 4 months during snow-free periods. Microenvironments altered by the patches were measured. Lab-experiments were performed to characterize the seed germination and seedling growth.

Larger patches decreased light intensity and temperature more and increased litter and water content. The large patches promoted the seed germination of the two species. Interspecific interactions, examined by a seed mixture experiment, showed that the interaction increased the seed germination on $M$. sinensis and decreased that on $P$. sachalinense. On the lab-experiments at three temperatures $\left(15,20\right.$ and $\left.25^{\circ} \mathrm{C}\right), M$. sinensis seeds germinated more at higher temperatures and obtained higher seedlings biomass. $P$. sachalinense germinated the seeds more at $20^{\circ} \mathrm{C}$ and grew faster at lower temperatures. The total biomass of the two species was reduced by shade that intercepted $50 \%$ of light intensity. The seed germination and seedling growth of these two species became higher on litter with $2 \mathrm{~cm}$ in depth than on no litter. Soil water supported seed germination when the seeds of these two species were mixed while the water reduced the growth of $P$. sachalinense seedlings. Therefore, the dry soils were suitable for their growths. In all the treatments, $P$. sachalinense seedlings showed higher mortalities than $M$. sinensis.

In conclusion, the large patches facilitated more to the colonization of pioneer plants via seed germination and growth. Large patches acted as a nursery supporting the natural regeneration in the disturbed area by improving litter accumulation, maintaining soil water, reducing strong light and/or protecting from heat.

Keywords : facilitation, Salix reinii, shrub patch sizes, volcano, Mt. Koma, microenvironment
\end{abstract}

\section{Introduction}

Volcanic eruption is one of the major disturbances on ecosystems and often leads primary succession. In the early stages of succession after catastrophic disturbances represented by volcanic eruptions, facilitation (positive interspecific interaction) performed by nurse plants has been highlighted because the mechanisms should be applied for ecosystem conservation and restoration (Ren $e t$ al., 2008). Nurse plants facilitate the establishments of colonizers by improving the environments that reduce inter-specific competition to nutrients and water and increase seed germination and seedling survival (Nunez et al., 1999; Barrera \& Smith, 2009).

Seedling stage is crucial to determine the fates in a life cycle. For example, two large perennials, Petasites japonicus and Polygonum sachalinense, show low seedling survivals on coarse volcanic ejecta on Mount Usu, northern Japan, soon after the eruptions (Tsuyuzaki \& Haruki, 2008). Therefore, facilitation at seedling stages is a key to determine vegetation development through ameliorating microenvironments (Nunez et al, 1999).

Nurse plants ameliorate both above-and below-ground microenvironments (Gomez-Aparicio et al 2005), i.e., light intensity, temperature and litter accumulation on the above-ground and water and nutrients in the below-ground environments (Franco and Nobel, 1989; Ren et al., 2008). They also have seed trap effects (Badano et al., 2016) supporting high seedling emergence (Pueyo et al., 2016). Shrubs often have facilitative effects by reducing interspecific competition and ameliorating microclimates and/or soils (Gomez-Aparicio, 2009; Butterfield and Briggs, 2011). On Mount Koma, northern Japan, a deciduous shrub, Salix reinii, has facilitative effects on colonizers by providing an ameliorated microclimate, increasing soil fertility and developing seedbank (Uesaka, 2004). The effects of shrub patches should be different with the sizes, although a few researches have been conducted. Mischantus sinensis Andersson and Polygonum sachalinense Fr. Schmidt et Maxim. are common herbs in northern Japan (Tsuyuzaki \& Hase, 2005) and develops their respective grasslands in northern Japan in the middle stages of succession (Tsuyuzaki 2005). These two herbs often established together. Therefore, the effects of patch sizes on the seed germination and seedling growth of cohabitants were examined by these two species. When these two species grow together, these two herb species should be interacted. The interaction was investigated by seed germination, seedling emergence and biomass allocation. In addition, these two herbs may accelerate the succession because they also have facilitative effects (Tsuyuzaki, 2005a; Barney et al., 2006).

Therefore, the effects of patch sizes on seed germination and seedling growth of these two species were investigated. Various environmental factors are altered by shrub patches, i.e., temperature, light, litter and water. To understand what environmental factors affected the regeneration of $M$. sinensis and $P$. sachalinense, the effects of each environmental factor were separately investigated on the seed germination and seedling growth in lab-experiment. The objectives were detecting: 1) the size effects of $S$. reinii patches on the seed germination and seedling growth of $M$. sinensis and $P$. sachalinense; 2 ) the alteration of environments under different-sized $S$. reinii patches; and 3) the mechanisms of factors altered by the patches on the seed germination and seedling growth of M. sinensis and $P$. sachalinense. 


\section{Materials and Methods}

Study area

Mount Koma is an active stratovolcano in the southern part of Hokkaido Island, Japan ( $42^{\circ} 04$ 'N, $140^{\circ} 42^{\prime} \mathrm{E}, 1140 \mathrm{~m}$ elevation). The climate is warm-cool temperate with $973 \mathrm{~mm}$ of annual precipitation in 2015 (Mori Climatological Observatory, $10 \mathrm{~m}$ elevation, 9 $\mathrm{km}$ from Mount Koma). From July to November in 2015, the mean annual temperature was $14.6^{\circ} \mathrm{C}$ (Japan Meteorological Agency, 2016). The last major eruption occurred in 1929 and the blast and debris avalanches completely destroyed the former vegetation. The vegetation recovery is slow and has not been attained the climax (Tsuyuzaki \& Hase, 2005).

Field experiments

All the field experiments were conducted on the southwestern slope between $750 \mathrm{~m}$ and $880 \mathrm{~m}$ elevations, where $S$. reinii patches were dominant, during early summer to early autumn in 2015 and 2016. Shade by the tree canopy was weak, because of less trees. In total, $20 \mathrm{~S}$. reinii patches of which areas were 0.97 to $4.12 \mathrm{~m}^{2}$ were selected for the survey. In addition, ten $1 \mathrm{~m} \times 1 \mathrm{~m}$ plots were established on the bareground, where the cover of $S$. reinii was less than $10 \%$, as control. In July 2016 when the plants grew well, seven and 23 soil samples were collected from baregrounds and patches ranging from $0.84 \mathrm{~m}^{2}$ to $2.50 \mathrm{~m}^{2}$, respectively, by a scoop. The samples were collected down to approximately $5 \mathrm{~cm}$ after removing litter if accumulated. Each sample was stored in a plastic bag until measured. The fresh weight of soil was measured soon after returning the laboratory. The samples were dried in an oven at $60^{\circ} \mathrm{C}$ for five days and weighted. Water content (\%) was calculated as: (fresh weight - dry weight)/(dry weight) $\times 100$. The remainders of soils were used for greenhouse experiments to test if the patches have a seed trap effect. Litter thickness was measured by selecting 5 random points inside of each patch, using a ruler and was calculated as the averaged thickness. Litter cover under the patches was visually estimated. Litter was collected randomly from the patches in July 2016.

Temperature and light intensity were measured at one-hour intervals by data loggers (HOBO UA-002-XX, Onset, Massachusetts, USA) underneath four S. reinii patches and on two baregrounds from July 22 to October 10 2015. Daily air temperatures and sunshine hours recorded at Mori Climatological Observatory were also used. Relative light intensity (RLI) was calculated by (the average of daily light intensity under patches) / (average of daily light intensity in bareground) $\times 100 \%$.

The seeds of $M$. sinensis were donated by Snow Bland Seed Co. (Sapporo, Japan). The seeds were harvested form a $M$. sinensis grassland near Sapporo in early autumn 2014. The seeds of $P$. sachalinense were collected from $P$. sachalinense grown on Mount Koma in October 2014. The seeds were kept in an incubator at $5^{\circ} \mathrm{C}$ until use. Before sowing seeds for experiment, germinating seeds in the incubator is conducted to check the seed viabilities. The seeds of $M$. sinensis and $P$. sachalinense were sown to each patch and to each bareground in July 2015. Seedling emergence and death were monitored until November in 2005. Cohabitant species were recorded in 19 randomly-established $2.5 \mathrm{~m} \times 2.5 \mathrm{~m}$ plots. The number of aboveground shoots on each species was counted in each patch or bareground.

Greenhouse experiments

To investigate the effects of seedling competition on the seed germination and seedling growth, the seeds of $M$. sinensis and $P$. sachalinense were sown solely (hereafter, single treatment) or mixed (mixture) on vermiculite as the substrates in pots $(5 \mathrm{~cm}$ in diameter) on the greenhouse. A total of 20 seeds were sown to each plot. On the single treatment, 20 seeds on a given species were sown to each pot. On the mixture treatment, 10 seeds of each species were sown to each pot. On each treatment, 10 replications were used.

The seed-sown experiments were conducted on the seeds of $M$. sinensis and $P$. sachalinense in the greenhouse to detect the effects of light intensity, litter and water supply on seed germination and seedling growth. Shade was developed by pots covered with black sheer nets that reduced ca $50 \%$ of light intensity. Litter collected from Mount Koma was spread over vermiculite with 0 , 1,2 and $3 \mathrm{~cm}$ in depths. The litter consisted of $S$. reinii leaves. Water was sprinkled five times every day approximately $5 \mathrm{ml} /$ pot each time. On water supply experiments, water was sprinkled five times (wet treatment) or three times every day (dry). Approximately $5 \mathrm{ml}$ of water was supplied to each pot at each sprinkle.

The effects of temperatures on seed germination were examined at a cycle of $10^{\circ} \mathrm{C} / 20^{\circ} \mathrm{C}(12 \mathrm{hr} / 12 \mathrm{hr}), 15^{\circ} \mathrm{C} / 25^{\circ} \mathrm{C}$ and $20^{\circ} \mathrm{C}$ $130^{\circ} \mathrm{C}$ in incubators. Hereafter, these three treatments are called $15^{\circ} \mathrm{C}, 20^{\circ} \mathrm{C}$ and $25^{\circ} \mathrm{C}$ based on the average. Discontinuous light was given to the seeds ( $12 \mathrm{hr}$ dark $/ 12 \mathrm{hr}$ light). Seedlings were counted every day for first one week and every week thereafter until no more seed germination occurred.

All the seedlings were harvested 70 days after the beginning of experiments except for 80 days under shade. The seedlings were separated into the aboveground and belowground parts, dried at $60^{\circ} \mathrm{C}$ in an oven for five days and weighed.

Soil samples were collected from the field in the patch and in the bareground, by a soil sampler of which volume was $80 \mathrm{~cm}^{3}$. Collected soils were spread on vermiculate in each pot. Water was sprinkled five times every day. After four months, seedlings emerged from the seedbank were counted and identified.

Statistical analysis

To examine the effects of patch size and seed mixture on the seed germination on each species in the field, generalized linear mixedeffects model (GLMM) was used. The response variable was the number of germinated seeds and the explanatory variables were patch size, time (September, October and November) and seed mixture. The random effect was patch and bareground codes. To test the effects of environmental factors on the seedling biomass, generalized linear model (GLM) was used. On each of the two species, seedling biomass was used as responsive variable and treatments (temperature, light intensity, litter thickness and tephra water 
content) as explanatory variables. Repeated-measures ANOVA was used to compare the seed germination patterns in the labexperiments. All the statistical analyses were performed using R software (version 0.99.451).

\section{Results}

Alteration of microclimate by $S$. reinii patch

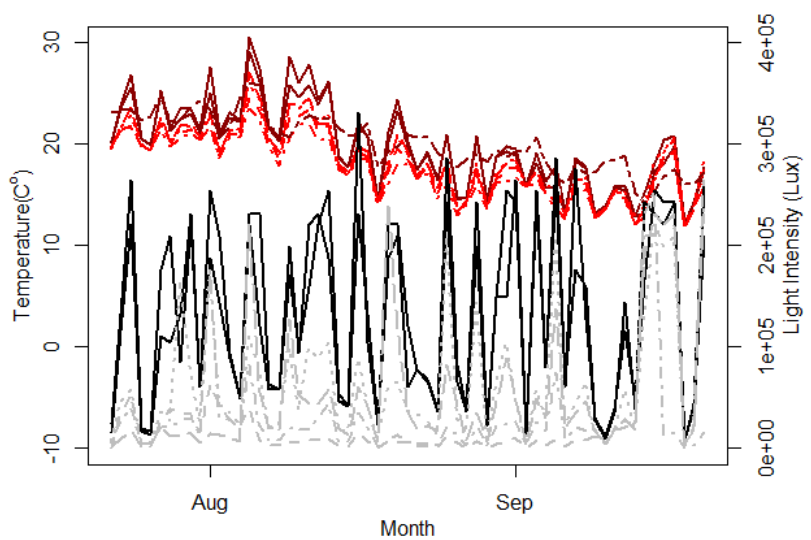

Figure 1. Mean daily temperature (reds) and light intensity (grayscale) measured on two baregrounds (darker-solid lines), four $S$. reinii patches $\left(1.21 \mathrm{~m}^{2}\right.$ patch $=$ dashed line, $1.37 \mathrm{~m}^{2}$ patch = dotted line, $1.99 \mathrm{~m}^{2}$ patch = dotdash line, $4.12 \mathrm{~m}^{2}$ patch = longdash line) and Mori Town Climate Observatory (twodash-dark red line) from July 2015 to September 2015. The first day (day=1) is July 222015.

S. reinii started the leaf flushing in late April and defoliated in late September in the two surveyed years. From mid-July to late August, the temperatures were higher on baregrounds than on the patches (Fig. 1). Afterwards, the temperatures differences among sites became narrower, due probably to the defoliation. The large patches reduced temperatures more than the small patches. The highest temperature was recorded at $30.6^{\circ} \mathrm{C}$ on the bareground on August 52015 and the lowest one was at $11.9^{\circ} \mathrm{C}$ in the $1.2-\mathrm{m}^{2}$ patch on September 18. The mean daily light intensity fluctuated with the sunshine hour (Fig. 1). The light intensity was correlated to the temperatures on the bareground. Relative light intensity (RLI, \%) was reduced with increasing patch size, with $19.4 \%$ in patch with size $2.0 \mathrm{~m}^{2}$ and $20.1 \%$ in $1.2 \mathrm{~m}^{2}$ shrub. However, the temperatures lowered with increasing patch sizes.

The volumes of litter ranged from $2.02 \mathrm{~cm}^{3}$ to $4.9 \mathrm{~cm}^{3}$ in the patches, while litter was not accumulated on the baregrounds. The large patch of which area was $2.5 \mathrm{~m}^{2}$ showed the highest litter volume $\left(8.4 \mathrm{~cm}^{3}\right)$ and cover $\left(2 \mathrm{~m}^{2}\right)$. Litter was accumulated more in larger patches, examined by the cover, thickness and amount (GLM, $\mathrm{p}<0.001$ ). Water content ranged from $8.0 \%$ to $23.9 \%$ in July 2016 and was higher in the patches than in the bareground, $15 \%$ and $11.72 \%$ respectively (GLM, $<0.01$ ). Since the measurements were conducted in summer, the high water content in the patches was derived mostly by the shade of S. reinii foliage.

\section{Effects of physical environments on seed germination}

The seed germination started nine days after sowing seeds on M. sinensis and 11 days on P. sachalinense at $25^{\circ} \mathrm{C}$ (Fig. 3). The germination delayed at $15^{\circ} \mathrm{C}$ on $M$. sinensis. The seeds of $M$. sinensis, independent of seed mixture, germinated most at the highest temperature, $25^{\circ} \mathrm{C}$ (ANOVA, $\mathrm{p}<0.001$ ). When the seeds were sown solely, $P$. sachalinense seeds germinated highest at $20^{\circ} \mathrm{C}$ $(\mathrm{p}<0.001)$.
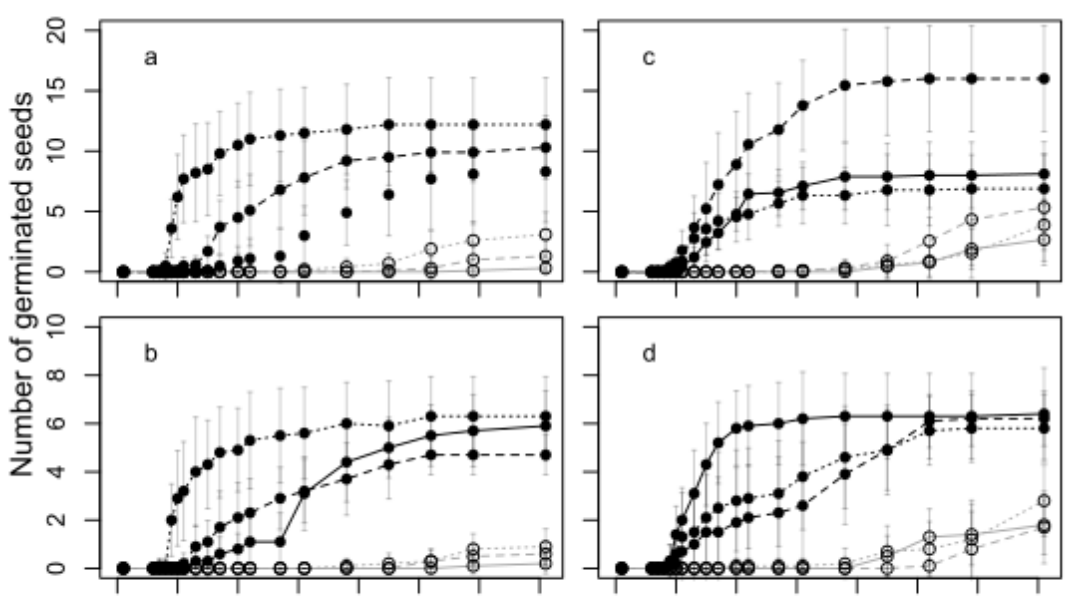

$\begin{array}{llllllllll}0 & 10 & 20 & 30 & 40 & 50 & 60 & 70 \quad 0 \quad 10 \\ \text { Days after sowing }\end{array}$ 
Figure 3. Seed germination patterns at three different temperatures on (a) M. sinensis seeds sown solely, (b) M. sinensis seeds sown with $P$. sachalinense seeds, (c) $P$. sachalinense sown seeds solely, and (d) $P$. sachalinense seeds sown with $M$. sinensis seeds. Mean numbers of seedlings (symbols) are shown width standard deviations (error bars). Solid, dashed and dotted lines show $15^{\circ} \mathrm{C}, 20^{\circ} \mathrm{C}$ and $25^{\circ} \mathrm{C}$. Black lines with filled circles and grey lines with circles indicate number of germinated seeds and number of dead seedlings, respectively.

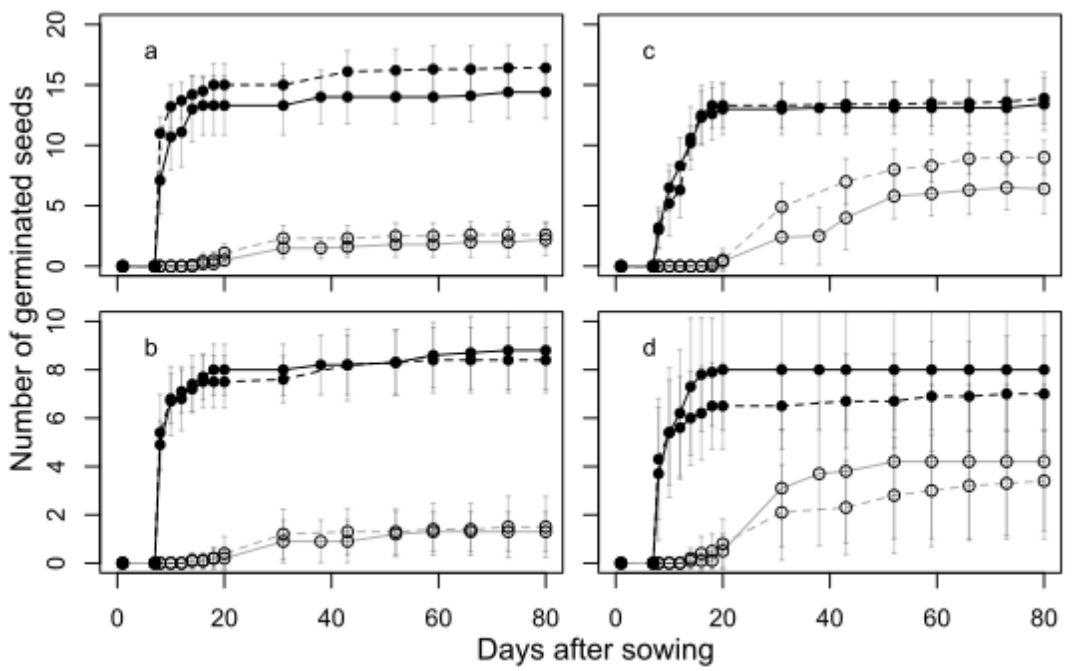

Figure 4. The effects of shade on the seed germination of (a) M. sinensis seeds sown solely, (b) $M$. sinensis seeds sown with $P$. sachalinense seeds, (c) $P$. sachalinense sown solely, and (d) P. sachalinense sown with M. sinensis seeds. Mean numbers of seedlings (symbols) are shown width standard deviations (error bars). Solid and interrupted lines show un-shaded and shaded treatments, respectively. Black lines with filled circles and grey lines with circles indicate number of germinated seeds and number of dead seedlings, respectively.

Shade changed the seed germination patterns on both the species (ANOVA, $\mathrm{p}<0.001$ ) (Fig. 4). The seeds of $M$. sinensis and $P$. sachalinense grown solely germinated more under the shade, indicating that direct sunlight was not suitable for the seed germination for these two species. However, the shade increased the seedling mortalities except unchanged mortalities on $P$. sachalinense grown with $M$. sinensis. The seed germination patterns were altered by the seed mixture, i.e., no significant differences in germination between the shade and no shade for $M$. sinensis (ANOVA, $\mathrm{p}<0.001$ ) and lower germination under shade for $P$. sachalinense $(\mathrm{p}<0.001)$. The mortalities of $P$. sachalinense were influenced by shade $(\mathrm{p}<0.001)$. The mortalities of $P$. sachalinense were higher under shade than under no shade when $M$. sinensis seedlings were absent. In contrast, the mortalities were higher when $M$. sinensis seedlings were present under no shade.

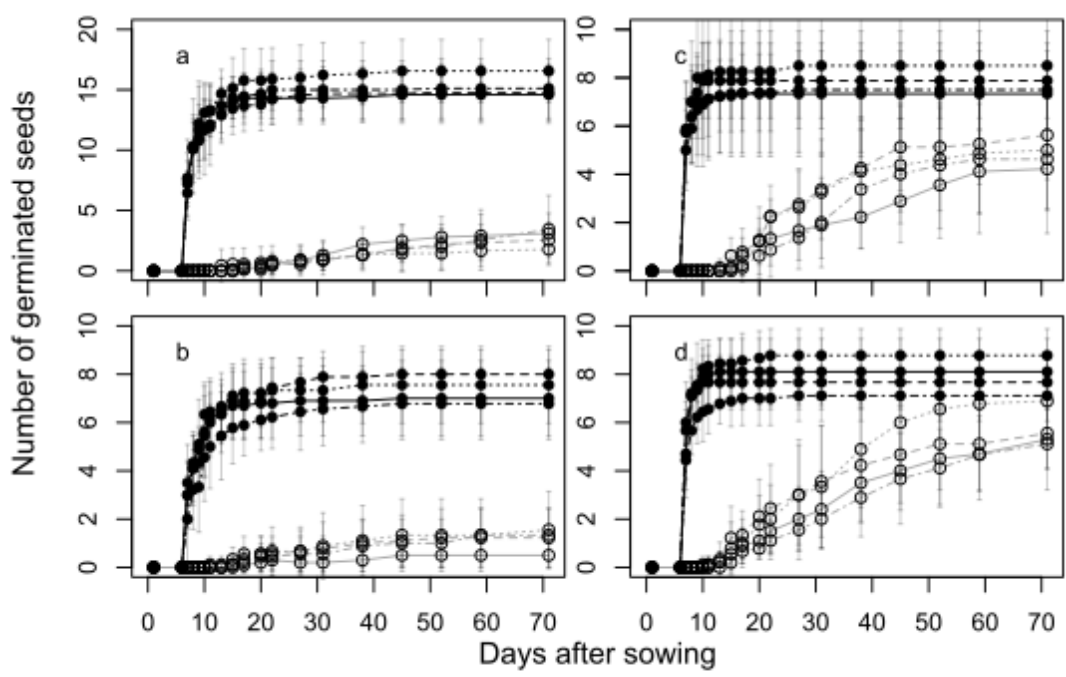

Figure 5. The effects of litter thickness on seed germination of (a) M. sinensis seeds sown solely, (b) M. sinensis sown with $P$. sachalinense seeds, (c) $P$. sachalinense seeds sown solely, and (d) P. sachalinense sown with $M$. sinensis seeds. Mean numbers of seedlings (symbols) are shown width standard deviations (error bars). Solid, dashed, dotted and dashed-dotted lines show that the litter thickness was 0, 1, 2 and $3 \mathrm{~cm}$. Black lines with filled circles and grey lines with circles indicate number of germinated seeds and number of dead seedlings, respectively. On the litter thickness, the seed germination was highest on $2 \mathrm{~cm}$ in depth on both the species (ANOVA, p $<0.001$ ) (Fig. 5) except 1 $\mathrm{cm}$ in depth on $M$. sinensis grown with $P$. sachalinense germinating earlier. Seed germination patterns differed between the dry and wet treatments on the two species (ANOVA, $\mathrm{p}<0.001$ ) (Fig. 6). M. sinensis and $P$. sachalinense had higher germination rates in the wet treatment but $P$. sachalinense grown solely germinated faster in the dry treatment. 


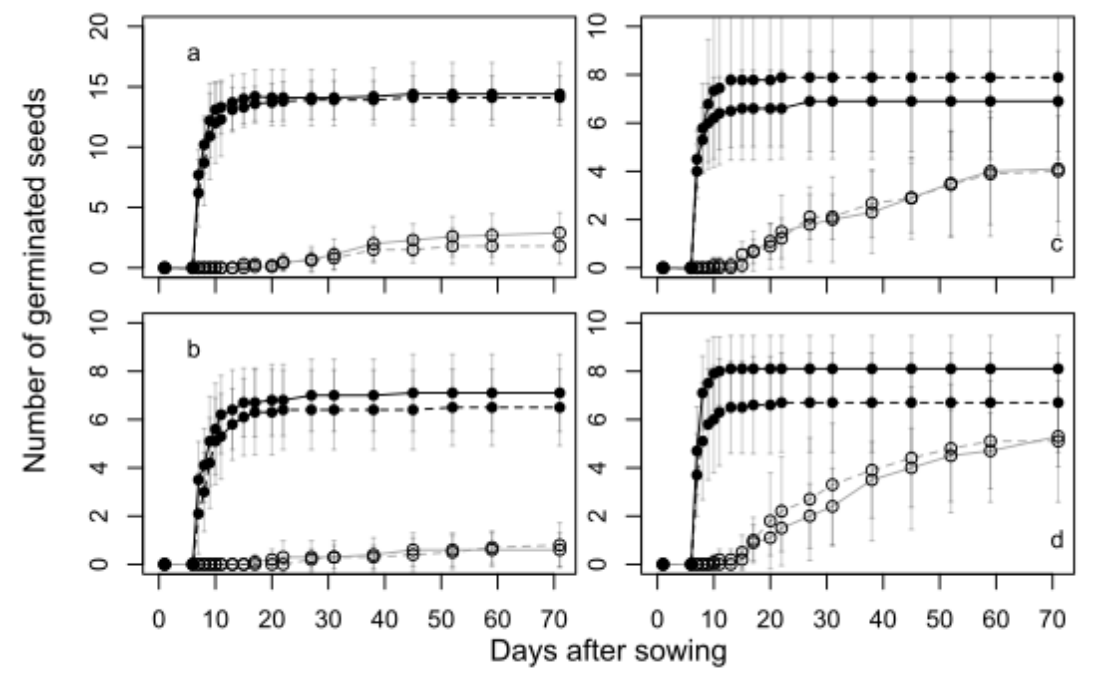

Figure 6. Water supply effects on seed germination of $M$. sinensis seeds sown solely (a), sown with $P$. sachalinense seeds (b), $P$. sachalinense seeds sown solely (c), and sown with M. sinensis seeds (d). Mean numbers of seedlings (symbols) are shown width standard deviations (error bars). Solid lines = wet treatment; interrupted lines $=$ dry. Black lines with filled circles indicate number of germinated seeds and grey lines with circles indicate number of dead seedlings.

Effects of physical environments on seedling growth

The seedling biomass of M. sinensis increased with increasing the temperatures with and without the seed mixture at $15^{\circ} \mathrm{C}$ to $25^{\circ} \mathrm{C}$ (GLM, $\mathrm{p}<0.05)$ (Fig. 7). The responses of seedling growth to the temperature were weakened when the seeds were mixed ( $\mathrm{p}<$ 0.001). P. sachalinense did not change the biomass among the examined temperatures, independent of the seed mixture $(\mathrm{p}>0.05)$. These results showed the possibility that $M$. sinensis seedlings did not colonize in areas when the temperatures were low. $P$. sachalinense seedlings emerged on areas with a wide range of temperatures more than $M$. sachalinense seedlings. Intraspecific competition reduced the biomass of $M$. sinensis seedlings $(\mathrm{p}<0.001)$ and did not affect the biomass of $P$. sachalinense $(\mathrm{p}>0.05)$.

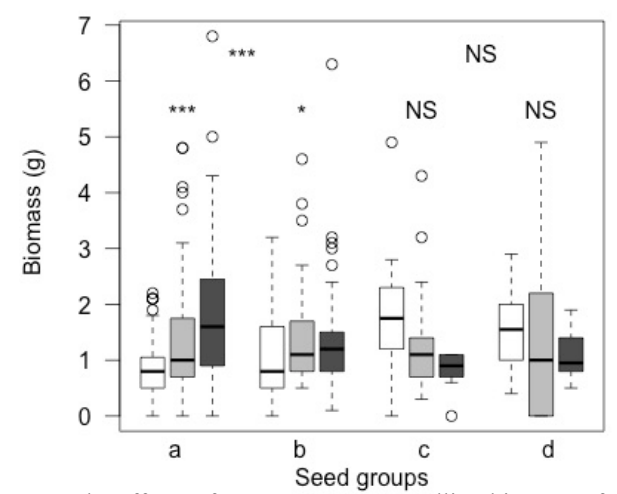

Figure 7. The effects of temperatures on seedling biomass of (a) M. sinensis grown solely ( $<0.001)$, (b) M. sinensis grown with $P$. sachalinense ( $<<0.05$ ), (c) $P$. sachalinense grown solely (NS), and (d) P. sachalinense grown with $M$. sinensis (NS). Blank, grey and dark grey indicate $15^{\circ} \mathrm{C}, 20^{\circ} \mathrm{C}$ and $25^{\circ} \mathrm{C}$, respectively.

Shade reduced the total seedling biomass of $M$. sinensis with and without the seed mixture (GLM, $\mathrm{p}<0.01$ ) (Fig. 8). The reduction of total biomass was derived by the reduction of both above-and below-ground biomass when the seeds were sown solely $(\mathrm{p}<0.01)$. However, the shade did not change the below-ground biomass when they grew with $P$. sachalinense $(\mathrm{p}>0.05)$. Therefore, the changes in total biomass were induced more by changes in the above-ground biomass. $P$. sachalinense did not change the total biomass and above-ground biomass by shade with and without $M$. sinensis $(\mathrm{p}>0.05)$, although the above-ground biomass was reduced greatly by shade when the seeds were sown with $M$. sinensis seeds $(\mathrm{p}<0.05)$. The below-ground biomass of $P$. sachalinense differed between shade and un-shade treatments $(\mathrm{p}<* * *)$, showing that this species maintained the biomass somehow by the allocation changes. 


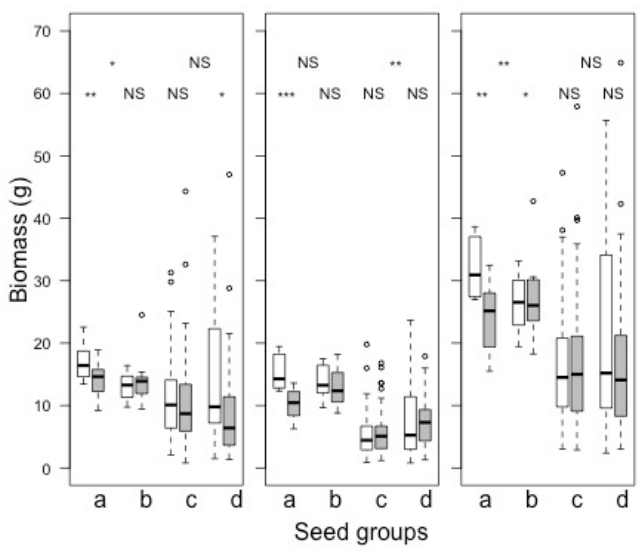

Figure 8. Box-whisker plots shown shade effects on the aboveground (left), belowground (middle) and total (right) biomass of (a) M. sinensis grown solely, (b) M. sinensis grown with $P$. sachalinense, (c) $P$. sachalinense grown solely, and (d) $P$. sachalinense grown with $M$. sinensis. White bars $=$ without shade; grey bars $=$ with shade. $* * *$ : significant at $\mathrm{p}<0.001 ; * *: \mathrm{p}<0.01 ; *: \mathrm{p}<0.05$; NS : Not significant, $\mathrm{p}>0.05$.

On $M$. sinensis seedlings, the biomass measured by the three parameters was not affected by the litter thickness ranging from 0 $\mathrm{cm}$ to $3 \mathrm{~cm}$ (GLM, $\mathrm{p}>0.05$ ) (Fig. 9). On $P$. sachalinense seedlings, when the seeds of the two species were mixed, the belowground biomass was highest on litter with $2 \mathrm{~cm}$ deep $(\mathrm{p}<0.05)$. The seedlings tended to be high biomass on $2 \mathrm{~cm}$ thick litter layer, although the biomass was not statistically different between litter thickness except the one case. Litter accumulation, as seen under $S$. reinii patches, was considered to be preferable for $P$. sachalinense seedlings.

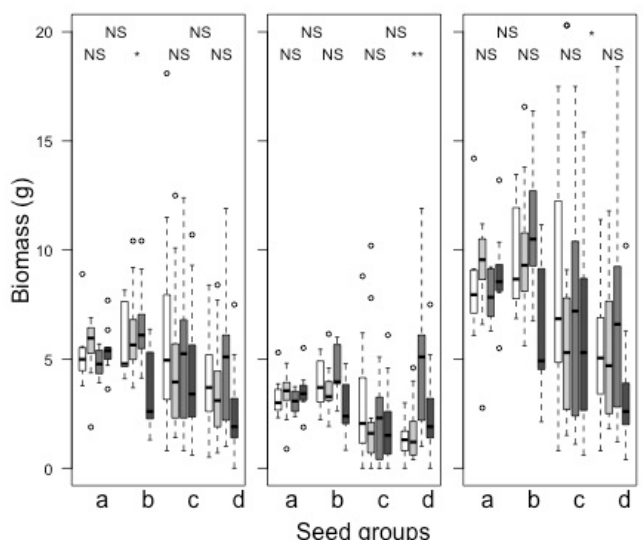

Figure 9. Box-whisker plots shown the effects of litter thickness on aboveground (left), belowground (middle) and total (right) biomass of (a) $M$. sinensis grown solely, (b) M. sinensis grown with P. sachalinense, (c) P. sachalinense grown solely, and (d) P. sachalinense grown with M. sinensis. Blank, light grey, grey and dark grey columns indicate litter thickness of 0,12 and $3 \mathrm{~cm}$. ${ }^{* * *}$ : significant at $\mathrm{p}<0.001 ;{ }^{* *}$ : $\mathrm{p}<0.01 ;{ }^{*}$ : $\mathrm{p}<0.05$; NS : Non-significant.

The effects of water on seedling growth.

The seedling biomass of the two species did not differ between the dry and wet treatments (GLM, $p>0.05$ ) (Fig. 10), showing that the water did not restrict the seedling growths on the two species in a surveyed range of water supply. The wet treatment decreasing the growth of $P$. sachalinense seedlings showed that excess water inhibited the growth.

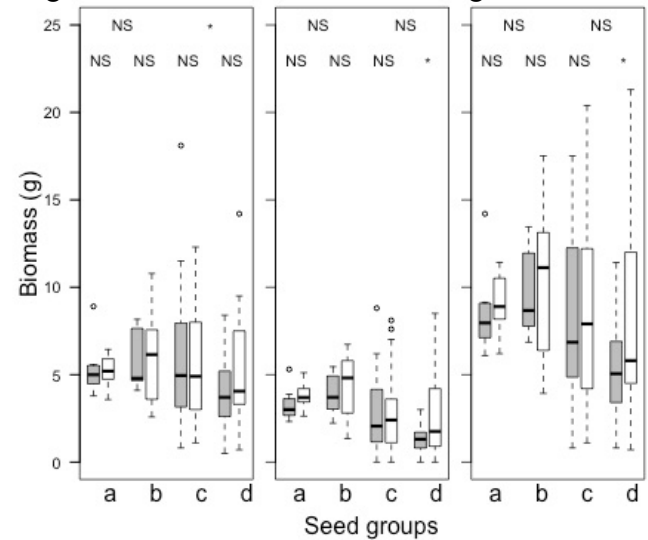

Figure 10. The effects of water supply on the aboveground (left), belowground (middle) and total (right) biomass of (a) M. sinensis, (b) M. sinensis mixture, (c) $P$. sachalinense, and (d) P. sachalinense mixture seedlings. Grey bars $=$ wet treatment; white bars $=$ dry. $* * *$ : significant at $\mathrm{p}<0.001 ; * *$ : $\mathrm{p}<0.01 ; *$ : $\mathrm{p}<0.05$; NS : Non-significant. 
Zero and five species emerged their seedlings on the soils collected from the baregrounds and patches, respectively. The five species were: Calamagrostis hakonensis (2 seedlings), Festuca rubra (16), Carex oxyandra (7), Erigeron acris (2), and Luzula capitata (2). The seedling densities were $0 / \mathrm{m}^{2}$ on the six bareground soils, $3 / \mathrm{m}^{2}$ on $0.87-\mathrm{m}^{2}$ patch, $1 / \mathrm{m}^{2}$ on $1.11 \mathrm{~m}^{2}-$ patch, $1 / \mathrm{m}^{2}$ on $1.15-\mathrm{m}^{2}$ patch, $6 / \mathrm{m}^{2}$ on $1.17-\mathrm{m}^{2}$ patch $1 / \mathrm{m}^{2}$ on $1.29 \mathrm{~m}^{2}$-patch $2 / \mathrm{m}^{2}$ on $1.36-\mathrm{m}^{2}$ patch $4 / \mathrm{m}^{2}$ on $1.56-\mathrm{m}^{2}$ patch $3 / \mathrm{m}^{2}$ on $1.86-\mathrm{m}^{2}$ patch $4 / \mathrm{m}^{2}$ on $1.97-\mathrm{m}^{2}$ patch $1 / \mathrm{m}^{2}$ on $2.09-\mathrm{m}^{2}$ patch $1 / \mathrm{m}^{2}$ on $2.11-\mathrm{m}^{2}$ patch and $2 / \mathrm{m}^{2}$ on $2.5-\mathrm{m}^{2}$ patch. Therefore, the safe sites for seed germination were the inside of patches.

\section{Discussion}

286 Patch size positively affects seed germination.

On the seed-sown experiments conducted in the field, the seed germination rates averaged $3.2 \%$ on $M$. sinensis and $4.3 \%$ on $P$. sachalinense in all the patches and plots. The seed germination rates increased with increasing patch sizes (GLMM, $<<0.001)$. When the seeds of these two species were mixed and sown, $M$. sinensis increased the seed germination and $P$. sachalinense decreased. The numbers of seedlings increased on the two species until September but decreased thereafter, due to death. The seedling mortalities averaged $69.2 \%$ on $M$. sinensis and $64.4 \%$ on $P$. sachalinense. The patch sizes increased germination of both the species $(\mathrm{p}<0.001)$. M. sinensis seedlings survived more than $P$. sachalinense seedlings $(\mathrm{p}<0.001)$, showing that $M$. sinensis was the winner on the competition at the seedling stage.

The facilitation of $S$. reinii patches tended to be size-dependent, shown by increasing the seedling germination of the examined two species with increasing the patch sizes. Facilitation by shrub patches is promoted by ameliorating microclimates and nutrients (Gomez-Aparicio et al, 2005) and capturing seeds (Franco \& Nobel, 1989; Uesaka \& Tsuyuzaki, 2004). However, these mechanisms are not activated physically if the size is small (Hao et al, 2016).

Since there was no litter on the bareground, the development of shrub patches was prerequisite to accumulate litter on the mountain slope. Although small S. reinii shrubs were established on the baregrounds with less than $10 \%$ in cover, they did not capture litter. The large patches retained more litter than the small ones. These results showed that the patch size was related to litter accumulation.

The S. reinii patches had seed trap effects as well as in arid regions (Burrows, 1994; Aguiar \& Sala, 1997; Hao, 2016), although the shoot development of M. sinensis is restricted in the patches (Uesaka \& Tsuyuzaki, 2004). The shrub patches affected all the examined microenvironments. Low air temperature and solar radiation derived by the shade should protect water loss by evapotranspiration. The seedling survivals of two shrubs, Ulex parviflorus (Fabaceae) and Santolina canescens (Asteraceae), are supported by high soil moisture particularly in dry seasons in Sierra Nevada, Spain (Gomez-Aparicio et al, 2005). Drought is often observed in summer on Mount Koma (Uesaka \& Tsuyuzaki, 2004). These results suggested that the soil moisture was critical for the seedling emergence and improved by the shrub patches.

\section{Seed germination is affected by simulated physical environmnent under shrub patches}

In this experiment, all the physical environment treated to the seeds were simulating how shrub patches create specific properties of microhabitats. Shrub patch altered microhabitat to several ways, such as lowering air temperature, reducing sunlight, accumulating litter, and storing more water in the soil.

We found that the optimal temperatures for seed germination were higher on $M$. sinensis than on $P$. sachalinense. The differences is likely to be related to their distributions, i.e., $P$. sachalinense has the southern limit in Honshu Island, Japan (Inoue et al., 1992) and M. sinensis is widespread in eastern Asia (Hirata et al, 2007). Furthermore, P. sachalinense grown with M. sinensis had the highest seed germination rate at $15^{\circ} \mathrm{C}$. This meant that the seed germination pattern was affected by biotic interactions. In addition, $P$. sachalinense seeds showed the highest seed germination at the lowest temperature, $15^{\circ} \mathrm{C}$, on the mixture treatment. These results suggested that inter-specific interaction occurred even at the seed germination stage.

Shade by $S$. reinii patches increased the seed germination of the two herbs in both the field and laboratory, showing that the direct sunshine inhibited the seed germination and weak shade was preferable for the seed germination. Direct sunshine often induces seed dormancy (Hart, 1988) to avoid seedling death by excess transpiration. The M. sinensis seeds used in this experiment did not require light for germination. However, the seed germination of $M$. sinensis is controversial; viz. the seed germination of $M$. sinensis requires light (Hsu 1989) while light has no effect on the germination (Christian, 2012).

The seeds of two herbs germinated well on 1-2 cm deep litter but did not on 3-cm deep litter, showing that the optimal litter thickness was present for the seed germination. Litter promotes seedling establishment in a certain range of thickness (Loydi et al. 2013) because of the water-holding capacity (Eckstein \& Donath, 2005). Litter more than $3 \mathrm{~cm}$ thick was not appropriate for the seed germination of the two examined species. The large amount of litter, more than $4 \mathrm{~g}$ of litter per pot, slows down seedling emergence of grassland and woodland species (Donath \& Eckstein 2008). Larger patches accumulated more litter on Mount Koma and supported seedling emergence more, suggesting that the litter accumulation under the patches was not overabundance and worked as safe sites for seed germination.

M. sinensis and $P$. sachalinense showed high germination rates in the wet treatment while the seed germination of them occurred gradually in the dry treatment. Delayed seed germination is often observed in disturbed areas to avoid the seedling death 
concurrently (Nomura \& Tsuyuzaki, 2015). The delayed seed germination is likely to be advantageous on the bareground to avoid the concurrent seedling death, although only a few seedlings emerged on the baregrounds due probably to strong drought.

Physical environments are less affecting seedling growth

High temperature increased the growth of $M$. sinensis but did not affect the growth of $P$. sachalinense in the lab-experiments. The seedling growth of M. sinensis is fast at $20-30^{\circ} \mathrm{C}$ in a greenhouse experiment (Aso, 1976). Shade did not change the growth of $P$. sachalinense seedlings and reduced the growth of $M$. sinensis seedlings, showing that $P$. sachalinense were more shade-tolerant at the seedling stage.

Polygonum aviculare seeds were unable to germinate without cold stratification (Bradford, 2005). Chilling or cold stratification shifts the requirement of light for the seed germination from high to low light intensities. Since the seeds of $P$. sachalinense were cold-stratified before sowing, the seeds established even under the shade if the characteristics of $P$. sachalinense seeds were comparable to those of $P$. aviculare.

The litter thickness did not affect the seedling biomass on the two species when growing alone. However, the litter reduced the aboveground and total biomass of $M$. sinensis grown with $P$. sachalinense. These results suggested that, under the shrub patches, $P$. sachalinense should be the winner to $M$. sinensis on the competition. Litter influences the water status in the soil, blocking contact between roots and soils, etc. (Facelli \& Pickett, 1991, Loydi et al, 2013). P. sachalinense is dicot and develops large rhizomes (Inoue et al., 1992), while M. sinensis is $\mathrm{C}_{4}$ perennial monocot grass developing numerous fibrous roots (Clifton-Brown \& Lewandowski, 2002). The root systems are totally different between these two species and seemed to be related to the effects of litter on their growths.

M. sinensis seedlings did not change the growth between the dry and wet treatments, showing that the growth adapted to a wide range of soil moisture. Interspecific competition did not change the growth of $M$. sinensis but reduced P. sachalinense growth. In dry seasons, litter retains water and therefore increases seedling emergence and growth (Loydi et al. 2013). The moderate amount of litter improved seedling establishment by storing enough water to break seed dormancy.

\section{Conclusions}

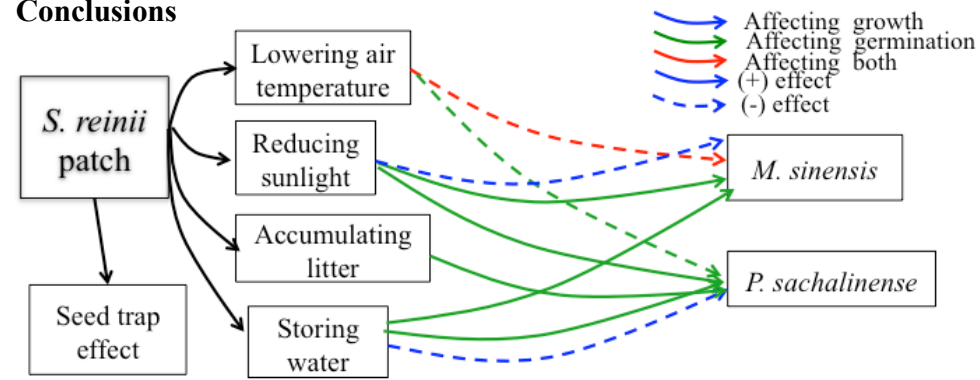

Figure 11. Patch size effects on the seedlings of $M$. sinensis and $P$. sachalinense through altering the environmental factors. Dotted, dashed and solid lines indicate interactions that affect growth, germination, and both. Black and grey lines indicate the positive and negative effects, respectively, based on the statistical results.

In conclusion, the patch effects of Salix reinii patches on the establishments of Mischantus sinensis and Polygonum sachalinense were: (1) the positive effects of $S$. reinii shrub patch size on seedling establishment were size-dependent, (2) $S$. reinii patches reduced air temperature and light intensity, increased litter amount and tephra moisture and trapped seeds, and (3) the patches providing moderate air temperature and high moisture in the tephra promoted the seed germination, and (4) litter accumulated by the patches supported the seedling growth. In addition, $M$. sinensis was the winner for the competition to $P$. sachalinense at the seedling stage. Not only at population level but also at landscape level, the size effects of facilitation should be focused more for the conservation and restoration of biodiversity.

\section{Acknowledgements}

We thank TaeOh Kwon, Lea Vegh, and Zhao Xin Xue for their invaluable help and support on fieldwork or collecting green house data. I am greatly indebted to my seniors, Dr. Fujinuma Junichi, Dr. Song Kun, and Dr. Ravi Mohan Tiwari, and also Dr. Kyle Tomlinson from Xishuangbanna Tropical Botanic Garden, Chinese Academy of Sciences who have helped me on understanding and doing statistical analysis. I also appreciate INPEX Scholarship Foundation for supporting my master study.

\section{References}

Aguiar, M. R. \& O. E. Sala. 1997. Seed distribution constrains the dynamics of the Patagonian steppe. Ecology 78:1 93-100. DOI: 10.1890/00129658(1997)078[0093:SDCTDO]2.0.CO;2

Aiken, G.E., and T.L. Springer. 1995. Seed size distribution, germination, and emergence of 6 switchgrass cultivars. J. Range Manage. 48:455-458. DOI: $10.2307 / 4002252$

An, G., A. Miyakawa, A. Kawahara, M. Osaki, \& T. Ezawa. 2008. Community structure of arbuscular mycorrhizal fungi associated with pioneer grass species Mischantus sinensis in acid sulfate soils: Habitat segregation along pH gradients. Soil Science and Plant Nutrition 54: 517-528. DOI: $10.1111 / j .1747-0765.2008 .00267 . x$

Aso, T. 1976. Studies on the germination of seeds of Miscanthus sinensis ANDERSS. Science reports of the Yokohama National University. Section II, Biological and geological sciences 23:27-37. 
Badano, E. I., O. R. Samour-Nieva, J. Flores, J. L. Flores-Flores, J. A. Flores-Cano, \& J. P. Rodas-Ortiz. 2016. Facilitation by nurse plants contributes to vegetation recovery in human-disturbed desert ecosystems. Journal of Plant Ecology $9: 5$ 485-497. DOI: 10.1093/jpe/rtw002

Barney, J. N., N. Tharayil, A. DiTommaso, \& P. C. Bhowmik. 2006. The biology of invasive plants in Canada. Canadian Journal of Plant Science 887-905. DOI: $10.4141 /$ CJPS06040

Barrera, E. D. L. \& W. K. Smith. 2009. Perspectives in Biophysical Plant Ecophysiology: A Tribute to Park S. Nobel. Mexico. Universidad Nacional Autonoma de Mexico, Mexico.

Berg, B., C. McChaugerty. 2003. Plant Litter: decomposition, humus formation, carbon sequestration. Springer. USA. DOI: 10.1007/978-3-54074923-3

Bertness, M. D., \& R. Callaway. 1994. Positive interactions in communities. Trends Ecol Evol. 9: 191-193. doi: 10.1016/0169-5347(94)90088-4

Birch, C. P. D., N. Vuichard, \& B. R. Werkman. 2000. Modelling the effects of patch size on vegetation dynamics: Bracken [Pteridium aquilinum (L.) Kuhn] under grazing. Annals of Botany 85: 63-76. DOI: 10.1006/anbo.1999.1081

Bradford, K. J. 2005. Threshold models applied to seed germination ecology. New Phytologist 165: 338-304. DOI: 10.1111/j.14698137.2004.01302.x

Brearley, F. Q., M. C. Press, \& J. D. Scholes. 2003. Nutrients obtained from leaf litter can improve the growth of dipterocarp seedlings. New Phytologist 160: 101-110. DOI: 10.1046/j.1469-8137.2003.00851.x

Burrows, C. J. 1994. Seed trapping in Ahuriri summit bush scenic reserve, Port Hills, western Banks Peninsula, 1985-1986. New Zealand Journal of Botany 32: 183-215. DOI: 10.1080/0028825X.1994.10410367

Butterfield, B. J. \& Briggs, J. M. 2011. Regeneration niche differentiates functional strategies of desert woody plant species. Oecologia 165: 477-487. DOI:10.1007/s00442-010-1741-y

Christian, E. J. 2012. Seed development and germination of Miscanthus sinensis. Iowa State University. Graduate theses and Dissertations. Paper 12880. DOI: 10.1.1.824.1622

Clifton-Brown, J.C., \& I. Lewandowski. 2002. Screening Miscanthus genotypes in field trials to optimise biomass yield and quality in Southern Germany. Eur. J. Agron. 16:97-110. DOI : 10.1016/S1161-0301(01)00120-4

Copeland, L. O., \& M. McDonald. 2001. Principles of seed science and technology. Springer Science+Business Media, LLC. 89. DOI: 10.1007/978$1-4615-1783-2$

del Moral, R., \& S. Y. Grishin, 1999. Volcanic disturbances and ecosystem recovery. In book: Ecosystems of disturbed ground, Chapter 5, Publisher: Elsevier Science. 137-160. Journal of Ecology 96: 272-280. DOI: 10.1046/j.1365-2745.2000.00499-3.x

Eckstein, R. L., \& T. W. Donath. 2005. Interactions between litter and water availability affect seedling emergence in four familial pairs of floodplain species. Journal of Ecology 93: 807-816. DOI: 10.1111/j.1365-2745.2005.01015.x

Ercoli, L., M. Mariotti, A. Masoni, \& E. Bonari. 1999. Effect of irrigation and nitrogen fertilization on biomass yield and efficiency of energy use in crop production of Miscanthus. Field Crop. Res. 63:3-11. DOI : 10.1016/S0378-4290(99)00022-2

Facelli, J. M., \& S. T. A. Pickett. 1991. Plant litter: Its dynamics and effects on plant community structure. Botanical Review 57: 1-32. DOI: $10.1007 / \mathrm{BF} 02858763$

Gomez-Aparicio, L., J. M. Gomez, R. Zamora, \& J. L. Boettinger. 2005. Canopy vs. soil effects of shrubs facilitating tree seedlings in Mediterranean montane ecosystems. Journal of Vegetation Science 16:191-198. DOI: 10.1111/j.1654-1103.2005.tb02355.x

Gomez-Aparicio, L. 2009. The role of plant interactions in the restoration of degraded ecosystems: a meta-analysis across life-forms and ecosystems. Journal of Ecology : 97 1202-1214. DOI: 10.1111/j.1365-2745.2009.01573.x

Hart, J. W. 1988. Light and plant growth. Springer. Netherland. 104. DOI: 10.1007/978-94-011-5996-8

Hao, H., R. Lu, Y. Liu, N. Fang, G. Wu, \& Z. Shi. 2016. Effects of shrub patch size succession on plant diversity and soil water content in the waterwind erosion crisscross region on the Loess Plateau. Catena : 144 177-183. DOI: 10.1016/j.catena.2016.05.015

Hirata, M., Hasegawa N., Nobami K., \& Sonoda T. 2007. Evaluation of forest grazing as a management practice to utilize and control Mischantus sinensis in a young tree plantation in southern Kyushu, Japan. Grassland science : 53 181-191. DOI: 10.1111/j.1744-697X.2007.00091.x

Hsu, F.H. 1989. Effects of light quality and duration on seed germination of Miscanthus species. Journal of Taiwan Livestock Research 22:21-37.

Inoue, M., H. Nishimura, H. H. Li, \& J. Mizutani. Allelochemicals from Polygonum sachalinense Fr. Schm. (Polygonaceae). Journal of Chemical Ecology 18 (10) : 1833-1840. DOI: 10.1007/BF02751107

Ito, S., Ishigami S., Mizoue N., \& Buckley G. P. 2006. Maintaining plant species composition and diversity of understory vegetation under stripclearcutting forestry in conifer plantations in Kyushyu, Southern Japan. Forest Ecology and Management : 231 234-241. DOI: 10.1.1.544.4030

Kellogg, C. H., S. D. Bridgham, \& S. A. Leicht. 2003. Effects of water level, shade and time on germination and growth of freshwater marsh plants along a simulated successional gradient. Journal of Ecology : 91 274-282. DOI: 10.1046/j.1365-2745.2003.00764.x

Kobayashi, K., \& Y. Yokoi. 2003. Shoot population dynamics of persisting clones of Mischantus sinensis in the warm-temperate region of Japan. Journal of Plant Research : 116 443-453. DOI: 10.1007/s10265-003-0119-1

Kwon, T., \& S. Tsuyuzaki. 2016. Differences in nitrogen redistribution between early and late plant colonizers through ectomycorrhizal fungi on the volcano Mount Koma. Ecological Research 31 (4). DOI: 10.1007/s11284-016-1364-9

Lenton, T. M. 2001. The role of land plants, phosphorus weathering and fire in the rise and regulation of atmospheric oxygen. Global Change Biology : 7 613-629. DOI: 10.1.1.562.7721

Loydi, A., R. L. Eckstein, A. Otte, \& T. W. Donath. 2013. Effects of litter on seedling establishment in natural and semi-natural grasslands: a metaanalysis. Journal of Ecology : 101 454-464. DOI: 10.1111/1365-2745.12033

Loydi, A., K. Lohse, A. Otte, T. W. Donath, \& R. L. Eckstein. 2013. Distribution and effects of tree leaf litter on vegetation composition and biomass in a forest-grassland ecotone. Journal of Plant Ecology : 1-12. DOI:10.1093/jpe/rtt027

Navarro-Cano, J. A., M. Verdu, C. Garcia, \& M. Goberna. 2015. What nurse shrubs can do for barren soils: rapid productivity shifts associated with a 40 years ontogenetic gradient. Plant Soil : 388 197-209. DOI:10.1007/s11104-014-2323-2

Nomura, N., S. Tsuyuzaki. 2015. Hares promote seed dispersal and seedling establishment after volcanic eruptions. Acta Oecologica 63:22-27. DOI: 10.1016/j.actao.2015.02.003

Nunez, C. I., M. A. Aizen, \& C. Ezcurra. 1999. Species associations and nurse plant effects in patches of high-Andean vegetation. Journal of Vegetation Science : 10 357-364. DOI: $10.2307 / 3237064$

Padila, F. M., \& F. I. Pugnaire. 2006. The role of nurse plants in the restoration of degraded environments. Frontiers in Ecology and the Environment 4 196-202. DOI: 10.1890/1540-9295(2006)004[0196:TRONPI]2.0.CO;2

Pueyo, Y., D. Moret-Fernandez, A. I. Arroyo, A. D. Frutos, S. Kefi, H. Saiz, R. Charte, M. D. L. Giner, \& C. L. Alados. 2016. Plant nurse effects rely on combined hydrological and ecological components in a semiarid ecosystem. Ecosphere 7 : 10 1-19. DOI: 10.1002/ecs2.1514

Ren, H., L. Yang, \& N. Liu. 2008. Nurse plant theory and its application in ecological restoration in lower subtropics of China. Progress in Natural Science : 18 137-142. DOI: $10.1016 /$ j.pnsc.2007.07.008

Ruprecht, E., \& A. Szabo. 2012. Grass litter is a natural seed trap in long-term undisturbed grassland. Journal of Vegetation Science 23: 495-504. DOI: $10.1111 / \mathrm{j} .1654-1103.2011 .01376 . x$ 
Serrano-Bernado, F., J. L. Rosua, \& M. Diaz-Miguel. 2007. Light and temperature effects on seed germination of four native species of Mediterranean high mountains (Spain). International Journal of Experimental Botany 76: 27-38.

Thorp, J. 1948. How soils develop under grass. In: Anderson, C. P. (Ed.), Grass: Yearbook of Agriculture. United States Department of Agriculture, US Government Printing Office, Washington, DC.

Tsuyuzaki, S. 1989. Analysis of revegetation dynamics in the volcano Usu, northern Japan, deforested by 1977-78 eruptions. American Journal of Botany 76: 1468-1477. DOI: $10.2307 / 2444434$

Tsuyuzaki, S. 1991. Species turnover and diversity during early stages of vegetation recovery on the volcano Usu, northern Japan. Journal of Vegetation Science 2: 301-306. DOI: 10.2307/3235920

Tsuyuzaki, Shiro, Titus, J. H. \& del Moral, R. 1997. Seedling establishment patterns on the Pumice Plain, Mount St. Helens, Washington. Journal of Vegetation Science : 8 727-734. DOI: $10.2307 / 3237378$

Tsuyuzaki, S. 2005. Miscanthus sinensis grassland is an indicator plant community to predict forest regeneration and development on ski slopes in Japan. Ecological Indicator 5:109-115. DOI: 10.1016/j.ecolind.2004.10.002

Tsuyuzaki, S. \& A. Hase. 2005. Plant community dynamics on the volcano Mount Koma, Northern Japan, after the 1996 eruption. Folia Geobotanica : 40 319-330. DOI: 10.1007/BF02804282

Tsuyuzaki, S. \& M. Haruki. 2008. Effect of microtopography and erosion on seedling colonization and survival in the Volcano Usu, Northern Japan, After the 1997-78 eruptions. Land Degrad. Develop. : 19 233-241. DOI: 10.1002/ldr.835

Tsuyuzaki, S., M. Matsuda, \& M. Akasaka. 2012. Effect of a deciduous shrub on microclimate along an elevation gradient, Mount Koma, northern Japan. Climate Research : 51 1-10. DOI: $10.3354 /$ cr01047

Uesaka, S. \& S. Tsuyuzaki. 2004. Differential establishment and survival of species in deciduous and evergreen shrub patches and on bare ground, Mt. Koma, Hokkaido, Japan. Plant Ecology (175) 165-177. DOI: 10.1007/s11258-005-4839-2

Washa, W. B., 2015. Potential of the dark as a factor affecting seed germination. International Journal of Science and Technology $5: 228-36$.

Xiong, S. \& C. Nilsson. 1999. The effects of plant litter on vegetation: a meta-analysis. Journal of Ecology : 87 984-994. DOI: 10.1046/j.13652745.1999.00414.x

Yoshii, Y. 1932. Revegetation of volcano Komagatake after the great eruption in 1929. Botanical Magazine, Tokyo : 46 208-216. DOI: $10.15281 /$ jplantres 1887.46 .208

\section{Author Contribution}

498 Mukhlish Jamal Musa Holle collected the field and experimental data and analyzed the result. Tsuyuzaki Shiro helped supervise the research and during research preparation. All authors discussed the results and contributed to the final manuscript 